\title{
Plagiarism literature review
}

\author{
Xin Zhang ${ }^{a}$, Xiang Xie ${ }^{b}$
}

School of Beijing Jiao tong University, Beijing 100043, China

\begin{abstract}
Keywords: Plagiarism; academic misconduct; academic Standard.
\end{abstract}
\begin{abstract}
Paper is an important manifestation of the researchers of scientific research, in today's booming research papers plagiarism is increasingly prominent, detrimental to the social atmosphere, tarnished academic atmosphere, seriously affected the image of the social science community, and academic plagiarism is not one of the manifestations of serious side behavior. This paper aims to domestic and foreign existing research reviewed in the context of the sort of academic research based on research experience to fully draw foreign scholars to form a comprehensive understanding of the problem, and the prospect of plagiarism research trends, in order to accelerate development of plagiarism research in China.
\end{abstract}

\section{Background}

In recent years, academic misconduct increasingly the subject of attention, in October 2015 the Chinese one hundred international papers were withdrawn a lot of influence, for which China Association for Science and other seven departments jointly issued the "five are not allowed" to regulate the papers published. Author of "plagiarism" as the search term, CNKI were retrieved in the journal articles and PhD thesis 454 Document Information. Wherein SCI source journals, EI source journals, core journals and periodicals CSSCI total 126, China outstanding doctoral thesis database Source 33, outstanding master's thesis database Source 295, covering higher education, scientific research enterprise economic management, and many other disciplines. The concept paper will plagiarism, plagiarism reasons, plagiarism governance, plagiarism vision four aspects are reviewed.

\section{The concept of plagiarism}

\subsection{Foreign definitions.}

European awareness of intellectual property rights relatively early 15th century northern Italian city for the introduction of a new invention or foreign inventors established a system of privileges, the formation of the early prototype of copyright and intellectual property laws [1]. The Oxford Dictionary of foreign studies recognized for the "plagiarism" interpretation of the term, generally considered synonymous with plagiarism and plagiarism Department, White House Office for Science and Technology (OSTP) [1] and other official policies and other scholars of the Rothwell $\mathrm{N}$ the study defines that the plagiarism issue refers to the articles of others, views, procedures, or other intellectual achievements may be used, but not for others to recognize the contribution of the intellectual achievements and considered not proper attribution become recognized plagiarism need condition [2] Heriot-Watt University (British), Wayne Booth $\mathrm{C}$ and other scholars on the initiative of plagiarism was found that whether conscious or unconscious, as long as when using someone else's words or ideas but did not indicate the original author, so lead readers to think that these words is your own, constitute plagiarism [3]. Charles Lipson on the basis of the above definition of plagiarism ideas were introduced that plagiarism behavior includes not only statements, evidence, data and other content plagiarism should also include opinions, ideas, philosophy and other ideological plagiarism the plagiarism of the object to expand the ideological level [4].

\subsection{Domestic definitions}

In 1981, under the auspices of Academician and several other well-known scientists, "Science Daily" launched the "science of spiritual civilization," the great debate, opened the domestic academia to explore the issue of precedent. With different foreign and domestic scholars for 
plagiarism definition controversial. Kuang Rongze one hand, money Xuhong other scholars and "academic ethics and academic misconduct, Huazhong University of Science and Technology process (Trial)" the provisions of other documents that "plagiarism" and "plagiarism" is not synonymous, through plagiarism the object's behavior was a clear distinction between the concept that focused on the content of the paper copy, referring to the disclosure, more complete copy steal other people's work behavior. [5] Focused on the thesis plagiarism thoughts and ideas, by changing the form of presentation and expression, violations of intellectual property rights of the original author of the paper. Some scholars on the other hand by the "People's Republic of China Copyright Law" and the influence of the Ministry of Culture "books and periodicals copyrighted pilot Bill" and other documents found plagiarism and copying system synonymous. That the two exist only in the manner and extent of the infringement on the difference [6], for copying and plagiarism can be distinguished by direct and indirect plagiarism and copying objects should be extended to the field of unpublished works [7].

I believe that the National Copyright Administration Copyright Management Division January 15, 1999 "issued on how to identify plagiarism replies," explains the definition of the concept of more accurate: Copyright Law alleged plagiarism is the same concept, "refers to the work of others or fragments of stolen works for he published."[8] In 2001 the newly revised" copyright law of People's Republic of China, "the original" plagiarism, plagiarism "was changed to" stealing someone else's work. "So, in the copyright system on plagiarism and plagiarism are synonymous [9]. In recent years, the rapid development of the author's thesis plagiarism, the "plagiarism" is defined as: the academic point of view of others, academic thought, academic achievements in their own name and not publicly indicate the source of the behavior. Including plagiarism, plagiarism, self-plagiarism [10], signed improper behavior, inappropriate references and partial plagiarism, the first to publish behavior and retaliation against whistleblowers malicious behavior [11].

\section{Causes of plagiarism}

Institutional system factors. Lack of credit system, the German public in 1934 on the establishment of credit reference agencies, credit file as a second identity cards, once the stain will have great trouble [12]. Part of universities and research institutions to establish a research ethics, but the lack of social credit system of norms, plagiarism, and plagiarism is not a common occurrence integrity, the status quo of research integrity worrying. Academic evaluation system malformations, popular science magazine "Scientific American" that the Chinese presence in the mass production of paper "paper factory." Our paper has formed industrial trading, transaction size of up to several billion dollars, behind such a large demand for paper is our highly administrative, utility management and academic evaluation system, are currently using the published level and measured by the number of teachers, research level of scientific research personnel and students, ignoring the paper itself academic value measure [13]. Low level academic institution, with Britain and the United States "as the science and scientific" ideology is different from my academic thought by bureaucratic influence, the academic value attached to political or economic value, the level of academic institution lower. Population expansion of low academic institution has seriously affected the level of improving academic quality, so that the "academic elite" turned into "public academic", resulting in low-level redundant, plagiarism and other issues [14]. coupled with the absence of accountability, the peer review system is not perfect, imperfect monitoring and disciplinary system, academic responsibility and academic obligations of College Teachers under the different roles is not clear, and therefore low risk of plagiarism, eventually some quick success researchers choose to take the risk [15].

Policies and regulations Factors: In some cases, academic plagiarism is not only a violation of academic ethics, but also a violation of copyright law and a violation of the copyright of others. Differences of thought and expression, the United States and other Western countries have been abide by academic plagiarism and dichotomy (Plagiarism- Copyright Infringement dichotomy) legal infringement: academic plagiarism is usually carried out by the self-discipline academic institutions, copyright infringement prescribed by national legislation. Content of academic plagiarism, including 
expression and thought, expression and copyright infringement, the ideological dichotomy (idea-expression dichotomy), on ideological plagiarism does not constitute copyright infringement. Public knowledge of the differences of fair use: Content of academic plagiarism include well-known in the public domain, but according to the Copyright Law, on the information known to the public use does not constitute copyright infringement. Copy number differences: plagiarism academic plagiarism in the work of others is not available for reasonable use of copyright restrictions, regardless of the number of plagiarism. In the field of copyright infringement, unauthorized use of other people's work, meet the "Copyright Law" Article 22, can be exempted by the fair use system. Recognized standards of academic plagiarism and copyright infringement that standard is inconsistent, both the judiciary and academia are the lack of academic plagiarism that standard [16]. Resulting in a large number of cases of plagiarism die a natural death, the real subject of "Copyright Law" and other relevant laws and sanctions thesis plagiarism rare.

Individual network factors: personal factors, the researchers driven by profit, for funding in published papers, access to employment opportunities, job promotion, increasing pressure on wages, colleagues competition faced is the result of plagiarism incentives [17]. for teachers of academic misconduct Governance College just stay in the moral restraint and the level of public opinion, for the supervision and control of behavior, most researchers rely on self-discipline and academic conscience, researchers and academic norms common sense of a lack of basic training, it is one of the factors leading to the phenomenon of plagiarism and other academic misconduct frequent [18]. Network element, using the Internet for scientific research is double-edged sword, bringing in more data and update information at the same time, the Internet also makes academic anomie, plagiarism is more common. Tools via the Internet, plagiarism no longer pay attention to the argument, argument, demonstration, and focus more on a pile of data. Technology wise, could be put together Papers Buyers pay. Inferior level, it will search site "stick it", "Encyclopedia" as the first position paper writing copy and paste large-scale, widespread use of the Internet such as "essay writing", "paper factory" and other more updated plagiarism academic anomie behavior surfaced [19].

\section{Plagiarism governance}

Strengthen the system construction. Against plagiarism and other academic misconduct, the United States, Denmark, Finland, Norway and Poland set up a special government official governing body; Australia, Germany, Canada, Britain, Japan and South Korea by academic institutions or foundations set up the appropriate management department. [20] In recent years, the State Council issued the "Opinions on the Construction of Social Credit System", the local government has issued relevant policies and regulations, the establishment of the Ministry of Education and other ministries Style Construction Commission and other departments, universities and research institutes to establish academic Committee and other agencies, academic credit system construction of China has already started [21]. Through academic separation of powers, the establishment of the academic community, the academic community was evaluated in accordance with the provisions of the researcher's academic ability and academic contribution, rather than blindly chase utilitarian academic achievements, the establishment of academic scientific evaluation system. From the United States to improve governance systems and autonomous institutions in Germany, our country can at the national level, funding agencies and research institutes hierarchy level, the establishment of three levels of research ethics committees or office, established to monitor the network of academic misconduct [22]. Furthermore, the increase academic plagiarism Undated University Evaluation sub-index down [23], clear plagiarism social responsibility, the responsibility of authors, editors liability, professional liability reviewer, and editor of the editorial responsibility [24], Justice participate in academic plagiarism governance institutions, academia and administrative bodies are also practical measures [25].

Improve policies and regulations. Academic plagiarism is not only a violation of academic ethics, but also a violation of copyright law, academic plagiarism containment, not only to self-discipline in the academic ethics, but also from a legal point of institutional seek his law [26]. from a legal policy 
making level, China's "Criminal Law", "Civil Law", "Intellectual Property Law", "Copyright Law", "Patent Law" and "copyright law" involves thesis plagiarism governance, the Ministry of Education national ministries issued "opinions on scientists Code of conduct" and other documents, more than 20 colleges and universities and research institutes publish relevant implementation details. From the applicable legal level, the relationship between intellectual property scholars contractual relationship with the "Civil Law", "Tort Liability Act" as the breakthrough point, put forward a way to bear civil liability for acts of plagiarism [27]. In the criminal system of governance as a starting point, presented to great harm behavior should be given criminal punishment [28]. From the interpretation of the legal level, the Chinese scholars think we should pay more attention to the interpretation and application of existing laws [29]. For the thesis plagiarism interpret provisions should not cover the academic perspective of legislative power to configure and enjoy academic establishment method to close legislative loopholes [30]. from right to relief level, we can learn from the provisions of "Australian Code of Conduct for Responsible Research", and adhere to the principle of fairness in the procedures provided by the course of the investigation and subsequent embodiments fair hearing and give appeal rights conferred by investigators relief right [3]. In procedural law level we can learn from the French Directorate General of INSERM research using local processing experts, in-depth investigation of the investigation procedure [31].

Enhance personal education. Social atmosphere aspects: To adhere to moral education and institutional constraints combine to continuously improve and standardize the system of academic honesty and universities, will advance the prevention and post education combined. Whitley and other American scholars of the four constituent elements of the atmosphere of academic honesty, that the integrity of the other schools in the areas of assurance to the acquisition of knowledge for the purpose of education to encourage overall moral development as the goal and to the honor code as the value standard, construction of academic integrity atmosphere has a certain significance [32]. Teachers and researchers: the researchers and teachers to use the spirit of truth and the pursuit of the highest academic lofty thoughts, leading teachers recognize and internalize their great mission, adhere to strict academic standards, really consciously abide by the academic norms. They fear culture of academic life and a strong sense of respect for the sanctity of knowledge, enhance academic authority, teachers can truly aspire to the highest academic standards of a free and critical reflection, to strengthen academic autonomy [33]. To strengthen the moral construction of teachers, play the first fences plagiarize role, not because of sympathy for graduation charity, let a scholarly poor Pinliu into the academic market [34]. Student education: Students from the standpoint of the establishment of student academic integrity and morality develop, cultivate students' cognitive level of academic integrity and ethics; self-recognition ability; self-construction capacity; the quality of self-evaluation capacity of the body [35]. Should also be established to promote healthy interaction between students and the network to prevent network copying paper production [19].

\section{Conclusion}

I believe that the current academic definition of plagiarism has not been accurately defined; the reasons for plagiarism generated by a more comprehensive overview, but did not touch the paper to measure academic value, the cost of plagiarism and other deeper reasons; prevention regulation measures operability is not strong, the lack of elaboration of specific tools, means, methods, and other technical aspects. Some scholars have been using multiple regression analysis [17], questionnaire [36], deviant theoretical models and competition model [37] and other quantitative research methods to undertake research, but has not changed the existing study used qualitative research methods quantitative Study less the status quo. Next, you should continue to carry out an introductory study of academic misconduct and research institutions in Europe and Japan and other countries and relevant policies and regulations, the experiences of developed countries, the concept of an accurate definition of plagiarism, learn advanced management mechanism, governance systems [38]. At the same time, there should be a new breakthrough in the study of the reasons plagiarism by citations, patent publication, plagiarism lawsuit, the value of academic research into the measure, the value of the 
infringement and plagiarism becomes clear cost Next research trends. The use of information economics text measurement methods approaches, policies quantitative research, text mining, multivariate statistical methods and research methods of game models, further enriching the quantitative research methods. Design and management systems for the collection as a whole, hierarchical management, a clear division of academic misconduct integrated governance system to provide research tools and information.

\section{Acknowledgment}

Funded by the Central University of Basic Research Fund for Special Funds (2015jbwy012).

\section{References}

[1] Xuan Gong. Historical Evolution of German intellectual property law [Dissertation]. Huazhong University of Science and Technology Law Commercial Law, 2011.

[2] American Science, Engineering and Public Policy Committee of how a scientist Liu Huajie translated Beijing: Beijing Institute of Technology Press, 2004.

[3] Heriot Watt Univerisity. Plagiarism Statement (Chinese version). http://www.hw.ac.uk/registry/resources/plagiarismguidechinese.pdf.

[4] Wayne C Booth, Gregory G Ka Luomu, Joseph M Williams. Study is an art. Chen Meixia, Bi Xu Qing, Xu Gan Lin translated Beijing: Xinhua Publishing society, 2009: 190.

[5] Chen Guangren. Academic "plagiarism" definition [J] Technology Review, 2010 (18): 120-121.

[6] China Science magazine deputy editor Shengli overseas development model of scientific and technical journals and characteristics of [N]. China Press reported.

[7] Wei Zhi. On the rights of copyright collective management organization Management Reflections on the revised draft of the Copyright Law [J] legal research (CENTRAL INSTITUTE OF POLITICAL SCIENCE), 1999 (03):

[8] NCAC reply on how to identify plagiarism to Qingdao Municipal Copyright Bureau [J] Heilongjiang Land Reclamation Teachers College, 2000 (02): 99.

[9] Copyright Law of People's Republic of China on amendments - 19th meeting of the Standing Committee of People's Congress _ Shi Zongyuan [J].

[10]Tao Keqiang to self-plagiarism say "no" [J] News Sentinel, 2013 (03): 93.

[11]Chang Siming. The references cited in academic misconduct analysis [J].

[12]He Chongyuan. Do not lose faith tradition [J] People's Forum, 2010 (34): 43.

[13]Xiong Binqi. Paper Factory - refraction deformity Academic Evaluation System [J].

[14] Gan Huibin. Mass academic - China Academic Institutionalization [J].

[15] Liu Yibo academic misconduct in research [J].

[16]Qi Aiming, Zhou Weimeng. On the two sides of academic plagiarism: academic norms and legal norms divided into perspective [J] Chongqing University (Social Science Edition), 2010 (06): 86-92.

[17]Chang Yaping, Jiang Yinbo. An Empirical Study of College academic misconduct behaviors influencing factors - factors based on individual data analysis [J] Science Studies, 2008 (06): 1238-1242. 
[18]Zhu Ying Academic Norm Education and Institutional Arrangement [Dissertation]. Nanjing University, 2013.182.

[19]Liu Lin. Students' Academic Morality network Factors Analysis and Countermeasures Reflections [J] Shaanxi Education (Higher Education Edition), 2012 (12): 77-78.

[20]Dong Jianlong, Ren Hongbo. Experience and Enlightenment of Foreign strengthening scientific integrity of the building [J] Science Foundation of China, 2007 (04): 223-228.

[21]Wang Zhongxing. Personal Credit System of Colleges and Universities to extend thinking [J].

[22]Huang Junying foreign combat academic misconducts and Inspiration to China [J] Impact of Science on Society, 2006 (04): 5-8.

[23]Wu Shulian. Evaluation of China University [J] 2009.

[24] Academic Journal Editors how to prevent academic misconduct [J].

[25]Liu Changqiu. scientific misconduct under Rule of Law: Causes and Countermeasures [J] Shandong University of Science and Technology (Social Science Edition), 2011 (05): 17-22.

[26] Fu Yazhuo, Li Huashu. Study from academic plagiarism and copyright law Governance [J] Higher, 2010, 28 (1): 113-115.

[27]Li Yunbo. Civil College Teachers' Research Misconduct [J] Shan Dong University of Science and Technology (Social Science Edition), 2011 (05): 11-16.

[28]Zhang Lan. Comparative Study of Legal Regulation of scientific misconduct. Huazhong University of Science and Technology, 2008.42.

[29] Criminal Regulation scientific misconduct system [J].

[30]Bai Qin. Teachers academic misconduct University Governance [Dissertation]. Southwest University Higher Education, 2011.156.

[31]Kuai Qiang. Initiatives of advocate for research integrity and France against academic misconduct [J] Education Forum, 2007 (05): 81-84.

[32] Whitley, B.E. (1998) .Factors associated with cheating among college students: A review Research in Higher Education, 39,235-274.

[33] Bai Qin. Teachers academic misconduct University Governance [Dissertation]. Southwest University Higher Education, 2011.156.

[34]Tang Xiaoxiang undergraduate plagiarism underestimated [J] Education and occupation, 2015 (01): 95.

[35]Fan Zeheng, Secretary-run education system environments show people his main discipline Law graduate academic integrity and academic ethics develop mechanisms and countermeasures [J] Degrees and Graduate Education, 2006,12: 40.

[36] Yan Guangcai Academic Corruptions of Cause and Prevention Mechanism [J] Education and Culture Forum, 2009, 1 (1): 122.

[37]Zhang Li, Wang Huaping. Model of academic misconduct [J]. Science Studies, 2007 (01): 32-37.

[38] Jiang Meishi, Tang Jun, Tang Li. From Professional Ethics to the institutional transformation of public policy - the United States to deal with scientific misconduct policies and regulations [J] China Science and Technology Forum, 2008 (12): 134-138. 